University of Wollongong

Research Online

Faculty of Science, Medicine and Health -

Papers: part A

Faculty of Science, Medicine and Health

$1-1-2018$

\title{
Monitoring the extent of vertical and lateral movement of human decomposition products through sediment using cholesterol as a biomarker
}

\author{
Susan Luong \\ University of Wollongong, sluong@uow.edu.au \\ Shari Forbes \\ University of Technology Sydney \\ James F. Wallman \\ University of Wollongong, jwallman@uow.edu.au \\ Richard G. Roberts \\ University of Wollongong, rgrob@uow.edu.au
}

Follow this and additional works at: https://ro.uow.edu.au/smhpapers

Part of the Medicine and Health Sciences Commons, and the Social and Behavioral Sciences

Commons

\section{Recommended Citation}

Luong, Susan; Forbes, Shari; Wallman, James F.; and Roberts, Richard G., "Monitoring the extent of vertical and lateral movement of human decomposition products through sediment using cholesterol as a biomarker" (2018). Faculty of Science, Medicine and Health - Papers: part A. 5253.

https://ro.uow.edu.au/smhpapers/5253

Research Online is the open access institutional repository for the University of Wollongong. For further information contact the UOW Library: research-pubs@uow.edu.au 


\title{
Monitoring the extent of vertical and lateral movement of human decomposition products through sediment using cholesterol as a biomarker
}

\author{
Abstract \\ Due to the lack of human decomposition research facilities available in different geographical regions, the \\ extent of movement of human decomposition products from a cadaver into various sedimentary \\ environments, in different climates, has not been able to be studied in detail. In our study, a human \\ cadaver was placed on the surface of a designated plot at the Australian Facility for Taphonomic \\ Experimental Research (AFTER), the only human decomposition facility in Australia, where the natural \\ process of decomposition was allowed to progress over 14 days in the Australian summer. Sediment \\ columns (approximately $1 \mathrm{~m}$ deep) were collected at lateral distances of $0.25 \mathrm{~m}, 0.5 \mathrm{~m}, 1.0 \mathrm{~m}$ and $2.5 \mathrm{~m}$ \\ in each of four directions from the centre of the torso. Plot elevation and weather data were also \\ collected. Each sediment column was subdivided, dried and homogenised. A sample was isolated from \\ each sediment subdivision, extracted with hexane, and the hexane extract cleaned with citrate buffer $(\mathrm{pH}$ \\ 3 ), filtered and spiked with cholesterol-D 7 internal standard. After derivatisation with BSTFA + 1\% TMCS, \\ cholesterol was monitored in the samples using targeted gas chromatography tandem mass \\ spectrometry analysis. A positive result for decomposition products was given if the cholesterol \\ abundance in the test sample was higher than that detected in the 'control' samples of a similar substrate \\ type collected prior to cadaver placement. Within the confines of the experimental design and the \\ measured parameters, lateral leaching was observed over distances of up to $2.5 \mathrm{~m}$ from the centre of the \\ torso, which was the maximum distance tested in the study. Vertical leaching was detected to depths of \\ up to $49 \mathrm{~cm}$ below the ground surface. Such data can aid the development of policies related to plot \\ sizing and sediment renewal and regeneration at other human decomposition facilities and at cemeteries. \\ The density and distribution of cholesterol surrounding the cadaver in this study can also help forensic \\ investigators interpret cases involving remains that have been moved or scavenged.

\section{Disciplines} \\ Medicine and Health Sciences | Social and Behavioral Sciences

\section{Publication Details} \\ Luong, S., Forbes, S. L., Wallman, J. F. \& Roberts, R. G. (2018). Monitoring the extent of vertical and lateral \\ movement of human decomposition products through sediment using cholesterol as a biomarker. \\ Forensic Science International, 285 93-104.
}


Monitoring the extent of vertical and lateral movement of human decomposition products through sediment using cholesterol as a biomarker

Susan Luong ${ }^{1 *}$, Shari L. Forbes ${ }^{2}$, James F. Wallman ${ }^{3}$ and Richard G. Roberts ${ }^{1,4}$

${ }^{1}$ Centre for Archaeological Science, School of Earth and Environmental Sciences, University of Wollongong, Wollongong, New South Wales 2522, Australia

${ }^{2}$ Centre for Forensic Science, University of Technology Sydney, PO Box 123, Broadway, New South Wales 2007, Australia

${ }^{3}$ Centre for Sustainable Ecosystem Solutions, School of Biological Sciences, University of Wollongong, Wollongong, New South Wales 2522, Australia

${ }^{4}$ Australian Research Council (ARC) Centre of Excellence for Australian Biodiversity and Heritage, University of Wollongong, Wollongong, New South Wales 2522, Australia

*corresponding author: sluong@uow.edu.au

Shari L. Forbes: Shari.Forbes@uts.edu.au

James F.Wallman: jwallman@uow.edu.au

Richard G. Roberts: rgrob@uow.edu.au

Highlights

- Movement of human remains through the underlying soil and sediment were monitored.

- Vertical leaching was detected up to a depth of $49 \mathrm{~cm}$ below the ground surface.

- The greatest extent of vertical penetration was found directly beneath the torso.

- Lateral leaching was detected $2.5 \mathrm{~m}$ from the torso centre; distance may be further.

- Methodology and data can be applied to environmental monitoring and forensic casework.

\section{Abstract}

Due to the lack of human decomposition research facilities available in different geographical regions, the extent of movement of human decomposition products from a cadaver into various sedimentary environments, in different climates, has not been able to be studied in detail. In our study, a human cadaver was placed on the surface of a designated plot at the Australian Facility for Taphonomic Experimental Research (AFTER), the only human decomposition facility in Australia, 
where the natural process of decomposition was allowed to progress over 14 days in the Australian summer. Sediment columns (approximately $1 \mathrm{~m}$ deep) were collected at lateral distances of $0.25 \mathrm{~m}$, $0.5 \mathrm{~m}, 1.0 \mathrm{~m}$ and $2.5 \mathrm{~m}$ in each of four directions from the centre of the torso. Plot elevation and weather data were also collected. Each sediment column was subdivided, dried and homogenised. A sample was isolated from each sediment subdivision, extracted with hexane, and the hexane extract cleaned with citrate buffer $(\mathrm{pH} 3)$, filtered and spiked with cholesterol- $\mathrm{D}_{7}$ internal standard. After derivatisation with BSTFA + 1\% TMCS, cholesterol was monitored in the samples using targeted gas chromatography tandem mass spectrometry analysis. A positive result for decomposition products was given if the cholesterol abundance in the test sample was higher than that detected in the 'control' samples of a similar substrate type collected prior to cadaver placement. Within the confines of the experimental design and the measured parameters, lateral leaching was observed over distances of up to $2.5 \mathrm{~m}$ from the centre of the torso, which was the maximum distance tested in the study. Vertical leaching was detected to depths of up to $49 \mathrm{~cm}$ below the ground surface. Such data can aid the development of policies related to plot sizing and sediment renewal and regeneration at other human decomposition facilities and at cemeteries. The density and distribution of cholesterol surrounding the cadaver in this study can also help forensic investigators interpret cases involving remains that have been moved or scavenged.

\section{Keywords}

Leaching, lipids, cholesterol, GC-MS, human decomposition, soil analysis 


\section{Introduction}

Following death, a cadaver undergoes a series of spontaneous post-mortem changes, whereby the soft tissue is disintegrated by the action of hydrolytic enzymes and bacteria originating from the body, as well as the depositional environment. Autolysis, putrefaction and liquefaction describe the processes that are observed, resulting in the release of decomposition products into the environment; these products consist of proteins, carbohydrates and lipids. The latter class of compounds make up $60-85 \%$ of the body's adipose tissue [1], and are relatively stable and persistent (in the environment) compared to proteins and carbohydrates due to their hydrophobic nature. Because of this, lipids have been used in forensic and archaeological contexts to search for chemical remnants of human and animal remains.

In the human body, $90-99 \%$ of the lipids in the adipose tissue are triacylglycerols [1]; as decomposition progresses, these compounds undergo hydrolysis to free the fatty acids from the glycerol backbone. The conversion of unsaturated fatty acids to saturated fatty acids by hydrogenation also occurs. These reactions have been associated with the formation of adipocere, a late stage post-mortem decomposition product observed as a greyish-white, wax-like substance [25]. Common biomarkers that have been used for detecting decomposition products, including adipocere, are the saturated and unsaturated $\mathrm{C}_{16}$ and $\mathrm{C}_{18}$ fatty acids [2-9], including the sodium, potassium, calcium and magnesium salts of the fatty acids $[3,5,6]$, as well as 10-keto and 10hydroxy analogues at significantly lower abundances [2-7, 10]. Myristic acid (C14:0) and margaric acid (C17:0) have also been detected, albeit at significantly lower abundances. The majority of decomposition chemistry studies utilise gas chromatography mass spectrometry (GC-MS) for the analyses of tissue (pig and human) and soil specimens [3, 4, 7-9], but liquid chromatography is an alternative technique [2]. Besides fatty acids and the neutral lipids, sterols such as cholesterol (found in significant abundances in animal cells relative to plant structures) have been investigated as potential markers for detecting decomposition products, and used with success to detect pig remains [11]. Eicocoprostanol has also been reported in human adipocere [10].

Understanding the vertical and horizontal movement of human decomposition products into the surrounding sedimentary substrate, and their subsequent persistence in the natural environment, is important in both research and practice. In the context of forensic science, biomarkers or altered environmental parameters associated with the decomposition process can be used to detect grave soil, which is particularly useful in cases involving remains that have been relocated or subject to scavenging by animals [12]. For example, biomarker analysis or the monitoring of environmental parameters can be used to test soil surrounding remains, to confirm that decomposition did, in fact, occur at the site of discovery. Furthermore, it can be used to determine whether soil found at a site where there are no remains nonetheless contains products of decomposition. A positive result can be used as physical evidence to demonstrate that the cadaver had been moved by either the perpetrator or scavenging animals. For facilities conducting human decomposition research, this information potentially assists the development of policies relating to plot sizing and sediment renewal and regeneration. This type of environmental monitoring can be extended to assist cemeteries with their plot usage strategies, particularly if space is limited [13]. In archaeological science, data associated with the extent of leaching of organic material from faunal remains would, for example, aid in the interpretation of use-residue findings on archaeological implements.

To our knowledge, only two studies have been conducted to investigate the extent of lateral movement of decomposition products through the soil: the analysis of soil nutrients associated with human cadavers at the Southeast Texas Applied Forensic Science (STAFS) research and training facility [14], and the analysis of fatty acids exuded by pig cadavers [9]. Both of these studies showed 
that decomposition products have a significant effect on the soil in contact with, and surrounding, the cadavers. In the former study, the slope of the grave site appeared to affect the nutrients detected, with some nutrients detected downslope of the human remains being significantly higher than control soils that were sampled upslope. Alteration of the soil environment caused by cadaver decomposition is also supported by a study conducted at the University of Tennessee Anthropological Research Facility, to shed light on the long-term effects of continuous human decomposition on the surrounding environment [15]. To examine the extent of vertical movement of decomposition products through sediment, a field leaching study monitoring the decomposition of a pig in a natural quartz sand environment has been carried out in Australia [16].

The extent of lateral and vertical movement of human decomposition products leaching from a human cadaver into different sedimentary environments, in different climates, has not been able to be studied in detail in Australia, due to the lack (until 2016) of human decomposition research facilities such as those located in Tennessee and Texas. The aim of our study was to provide insights into this subject matter by carrying out a leaching study at the recently established Australian Facility for Taphonomic Experimental Research (AFTER), the only human decomposition facility in Australia and the Southern Hemisphere. In our study, a human cadaver was placed on the surface of a designated plot and allowed to decompose in the Australian summer. Sediment samples were collected and analysed using a gas chromatography tandem mass spectrometry (GC-MS/MS) method, targeting cholesterol. These data were then used to propose the probable zone of leaching around the cadaver in the northern, southern, eastern and western directions.

\section{Materials and methods}

\subsection{Site description}

AFTER is situated in the Hawkesbury region of New South Wales, Australia ( $\left.33^{\circ} 38 \mathrm{~S}, 150^{\circ} 39 \mathrm{E}\right)$. The research area consists of open eucalypt woodland, defined as Cumberland Dry Sclerophyll Forest. The site encompasses approximately 4.86 hectares of land surrounded by a high-security fence with CCTV cameras operating continuously.

\subsection{Donor description}

The human cadaver used in this study was acquired through the Body Donation Program, overseen by the Surgical and Anatomical Science Facility (SASF) at the University of Technology Sydney (UTS). Consent was provided by the donor to use their remains for the purposes of research at AFTER, in accordance with the NSW Anatomy Act 1977. The research undertaken at AFTER was covered under the UTS Human Research Ethics Committee Program Approval (UTS HREC REF NO. ETH15-0029).

A frozen donor was used for the study. The remains were frozen soon after death and completely thawed in the laboratory (at approximately $18^{\circ} \mathrm{C}$ ) prior to arrival at AFTER. The period between death and placement was 14 days. The donor was a Caucasian male aged 64 years. His height was $186 \mathrm{~cm}$ and weight was approximately $90 \mathrm{~kg}$. The donor had died of natural causes and showed no visible signs of decomposition at the time of placement.

\subsection{Positioning of the cadaver}

The cadaver was placed at AFTER during 2-15 February, 2016 (late summer). The body lay in the supine position on the soil surface, head facing west, with the middle of the torso located in the centre of a $5 \times 5 \mathrm{~m}$ plot. The arms were positioned slightly away from the torso and the feet were 
placed $0.8 \mathrm{~m}$ apart. The body was unclothed and an anti-scavenging cage was used to prevent avian scavenging, while still allowing invertebrate scavenging of the remains. Small and large mammal scavenging was prevented by the high-security fence surrounding AFTER. The body remained in this configuration before it was moved for the collection of sediment samples. The 14-day period used in this study aimed to encompass the active decay phase of decomposition and the greatest period of leaching.

\subsection{Collection of the sediment columns}

A power auger was used to collect vertical columns of sediment (to a depth of approximately $1 \mathrm{~m}$ ) beneath and in the immediate vicinity of the body. Prior to cadaver placement on the surface of the plot, four evenly-spaced 'control' sediment columns were obtained from the outskirts of the western perimeter. Fourteen days after cadaver placement, another 17 sediment columns were collected: one from beneath the middle of the torso (designated as the origin core), and 16 from distances of $0.25 \mathrm{~m}, 0.5 \mathrm{~m}, 1.0 \mathrm{~m}$ and $2.5 \mathrm{~m}$ from the origin, in the northern, eastern, western and southern directions. The four sediment columns taken $2.5 \mathrm{~m}$ away from the origin (i.e., N-2.5, E-2.5, S-2.5 and W-2.5) aligned with the perimeter of the $5 \times 5 \mathrm{~m}$ plot. Four columns (N-0.25, E-0.25, E- 0.5 and $\mathrm{W}-0.25$ ) were extracted from within the cadaver decomposition island (CDI), defined as regions in the soil directly below and around a decomposing corpse [14]. Two columns lay just outside the $\mathrm{CDI}$, between the legs (W-0.5) and the area between the left arm and torso (S-0.25). The equipment was thoroughly cleaned with wipes and then acetone in between the collection of the sediment columns. Also, samples collected furthest from the CDI were collected first, as these should have the lowest abundance of decomposition products, if any at all. These two measures minimised the possibility of cross-contamination that could have been caused by the coring technique.

The columns were subdivided into sections of approximately $5 \mathrm{~cm}$ in thickness. Where natural sedimentary boundaries were clearly observed, we avoided cross-cutting these boundaries by making sections so that the different strata remained separated from each other. Each section was analysed using GC-MS/MS.

\subsection{Evaluation of the soil and sediment matrix}

Grain size, $\mathrm{pH}$, redox potential (Eh) and electrical conductivity (EC) measurements were acquired for 20 soil and sediment samples sectioned from two control columns (C-1 and C-3). These data allowed an internal comparison of the physical and physicochemical characteristics of the soils and sediments found at AFTER to be carried out, and were used to aid interpretation of the GC-MS/MS data.

\subsubsection{Grain size analysis}

A Malvin Mastersizer 2000 particle size analyser was used to determine the average grain size and sand, silt and clay content of the samples. Following a background measurement, a sample was introduced into the system so that a $10-20 \%$ obscuration of the laser beam was achieved (using water as the dispersant) before data acquisition. Within each run, five sets of data were collected to generate a set of averaged results. The system was thoroughly cleaned between each analysis. Particles larger than $2 \mathrm{~mm}$ in diameter (gravels) are not suitable for measurement using the Mastersizer, but we noted their occurrence in the sediment columns.

\subsection{2 $\mathrm{pH}$, Eh and EC analyses}

Portable ORP/temperature and pH/EC/TDS meters (Hanna ${ }^{\circledR}$ Instruments: Castle Hill, NSW, Australia) were used to acquire $\mathrm{pH}$, Eh and $\mathrm{EC}$ data for the samples. Suspensions were prepared by combining 
$10 \mathrm{~g}$ of the sample with $30 \mathrm{~mL}$ deionised water (1:3 ratio). For each sample, three measurements of each test parameter were obtained over $5 \mathrm{~min}$, and the average (arithmetic mean) results were reported. The meters were calibrated prior to use and cleaned between samples.

\subsection{Determination of the slope of the plot}

A Leica TS06plus total station operated with EDMwin software [17] was used to collect elevation data. A total of 112 points covering the plot and the immediate surrounding area (in a grid pattern) was recorded with the total station and a prism, and the slope of the plot was calculated from these survey data.

\subsection{Collection of weather data}

Temperature and rainfall data were collected using a $\mathrm{HOBO}^{\circledR}$ No Remote Communication weather station base with sensors (OneTemp), and included hourly measurements of ambient temperature $\left({ }^{\circ} \mathrm{C}\right)$ and rainfall $(\mathrm{mm})$.

\subsection{GC-MS/MS analysis}

The procedure was adapted from a previously validated method developed for the analysis of low molecular weight lipids [18], with some deviations to the sample extraction and GC gradient temperature program. A liquid-liquid extraction step with citrate buffer was incorporated as an additional clean-up step, and the initial GC oven temperature was increased.

\subsubsection{Reference standards, chemical reagents and materials}

Solid cholesterol ( $\geq 99 \%)$, citric acid monohydrate $\left(\mathrm{C}_{6} \mathrm{H}_{8} \mathrm{O}_{7} \cdot \mathrm{H}_{2} \mathrm{O}\right)$ and sodium citrate tribasic dihydrate $\left(\mathrm{C}_{6} \mathrm{H}_{5} \mathrm{O}_{7} \mathrm{Na}_{3} .2 \mathrm{H}_{2} \mathrm{O}\right)$ were purchased from Sigma Aldrich (Castle Hill, NSW, Australia). Cholesterol- $\mathrm{D}_{7}(>$ 99\%) was sourced from Avanti Lipids (Alabama, USA). Acetonitrile (LC-MS grade), n-hexane (AnalaR NORMAPUR ${ }^{\circledR}$ ACS) and Whatman ${ }^{\mathrm{TM}} \mathrm{pH} 0-14$ non-bleed universal indicator strips were acquired from VWR International (Tingalpa, QLD, Australia). O-bis(trimethylsilytrifluoroacetamide) with $1 \%$ trimethylchlorosilane (BSTFA $+1 \%$ TMCS) derivatising agent was sourced from United Chemical Technologies (Bristol, Pennsylvania, USA).

\subsubsection{Preparation of the calibrator standard set}

A $1 \mathrm{mg} / \mathrm{mL}$ cholesterol stock standard was prepared by transferring $5 \mathrm{mg}$ of cholesterol into a $5-\mathrm{mL}$ volumetric flask, and made up to the mark with hexane. Using serial dilution, calibrator standards were prepared at eight levels: $0.1,1,5,10,100,1000,5000$ and $10,000 \mathrm{ng} / \mathrm{mL}$. Two quality control (QC) standards at 50 and $3000 \mathrm{ng} / \mathrm{mL}$ were prepared separately from the calibrator standards. A 200 $\mu \mathrm{g} / \mathrm{mL}$ cholesterol- $D_{7}$ internal standard stock solution was prepared and used to make a $10 \mu \mathrm{g} / \mathrm{mL}$ working solution. A reagent blank sample (1 mL hexane), along with $1 \mathrm{~mL}$ of each of the calibrator and QC standards, were spiked with $100 \mathrm{ng} / \mathrm{mL}$ of cholesterol- $D_{7}$. The samples were mixed with a vortex mixer, dried down under a gentle stream of nitrogen gas and derivatised on a heating block with $40 \mu \mathrm{L} \mathrm{BSTFA} / 1 \%$ TMCS and $10 \mu \mathrm{L}$ acetonitrile, at $70^{\circ} \mathrm{C}$ for $30 \mathrm{~min}$. The samples were injected directly into the GC-MS.

\subsubsection{Preparation of the citrate buffer $(\mathrm{pH} 3)$}

A $0.1 \mathrm{M}$ solution of citric acid monohydrate was prepared by dissolving $2.1014 \mathrm{~g}$ of the solid in Milli$\mathrm{Q}^{\circledR}$ water in a $100-\mathrm{mL}$ volumetric flask. Similarly, $100 \mathrm{~mL}$ of $0.1 \mathrm{M}$ sodium citrate tribasic dihydrate was made by dissolving $2.9412 \mathrm{~g}$ of the solid. The citrate buffer was then prepared by mixing $82 \mathrm{~mL}$ 
of the citric acid solution with $18 \mathrm{~mL}$ of the sodium citrate solution. The $\mathrm{pH}$ of the solution was confirmed using universal indicator strips.

\subsubsection{Preparation of sediment samples}

Sediment samples were dried, homogenised and $0.2 \mathrm{~g}$ of each sample was transferred into a 7-mL screw-top vial (Sigma-Aldrich: Castle Hill, NSW, Australia). Hexane $(2 \mathrm{~mL})$ was added to the vials and the samples were sonicated for $20 \mathrm{~min}$. The supernatant from each sample was isolated, $2 \mathrm{~mL}$ of citrate buffer $(\mathrm{pH} 3)$ was added and the samples were mixed on a roller mixer for $20 \mathrm{~min}$. They were subsequently left to stand on the bench for $10 \mathrm{~min}$ to facilitate the separation of the organic and aqueous phases. Each hexane fraction was filtered through a $0.22 \mu \mathrm{m}$ hydrophobic syringe filter unit (MicroAnalytix: Taren Point, NSW, Australia), and $1 \mathrm{~mL}$ of each sample was fortified with $100 \mathrm{ng} / \mathrm{mL}$ of cholesterol- $\mathrm{D}_{7}$. The samples were processed in the same manner as the calibrator standard samples for GC-MS analysis.

\subsubsection{Data acquisition and processing}

Samples were analysed using an Agilent Technologies 7890 GC system coupled to a $7000 \mathrm{GC} / \mathrm{MS}$ triple quadrupole mass spectrometer, configured in multiple reaction monitoring (MRM) mode. Following a $1 \mu \mathrm{L}$ injection of the samples in pulsed split mode (split ratio = 10:1), chromatographic separation was achieved using an $\mathrm{Rxi}^{\circledR}$-5Sil MS 1,4-bis(dimethylsiloxy)phenylene dimethyl polysiloxane fused silica column ( $20 \mathrm{~m} \times 0.18 \mathrm{~mm} \times 0.18 \mu \mathrm{m}$; Restek: Bellefonte, Pennsylvania), with a gradient temperature program. The initial temperature of $200^{\circ} \mathrm{C}$ was held for $3 \mathrm{~min}$, and subsequently increased at a rate of $30^{\circ} \mathrm{C} / \mathrm{min}$ to $315^{\circ} \mathrm{C}$, and held again for $3 \mathrm{~min}$, for a total run time of $9.83 \mathrm{~min}$. During the analyses, both the front inlet and auxiliary heater and source temperatures were set at $270^{\circ} \mathrm{C}$ and $280^{\circ} \mathrm{C}$, respectively. The inlet and injection pulse pressures were maintained at 30.177 and 35 psi, respectively. The septum purge flow and helium carrier gas flow were held at 3 and $1.4 \mathrm{~mL} / \mathrm{min}$, respectively. Data acquisition commenced after a 3-min solvent delay, and molecular fragmentation was induced using a standard electron ionisation (EI) energy of $70 \mathrm{eV}$. Three MRM transitions were used to monitor cholesterol as well as cholesterol- $D_{7}$ (a total of six transitions, with 1.8 cycles/s scan rate). The quantifying transition selected for cholesterol was 329 $>95$ (collision energy $(C E)=25 \mathrm{eV}$ ), and the two qualifying transitions were $368->353(\mathrm{CE}=15 \mathrm{eV}$ ) and $368->339(C E=15 \mathrm{eV})$. The quantifying and two qualifying transitions used for cholesterol- $\mathrm{D}_{7}$ were $336->95(C E=20 \mathrm{eV}), 375->213(\mathrm{CE}=15 \mathrm{eV})$ and $375->255(\mathrm{CE}=15 \mathrm{eV})$, respectively. Each sample was analysed in duplicate and the average (arithmetic mean) cholesterol concentration was determined.

The Agilent MassHunter ${ }^{\circledast}$ quantitative software package was used for data processing. Data obtained from the calibrator standards were fitted with linear regression curves with correlation coefficients of $\geq 0.99$, using a $1 / x$ weighted least-squares model. Cholesterol was quantified in the hexane extract, and expressed as mass of cholesterol (ng) extracted from the sediment (g) to obtain an approximate cholesterol concentration in the sediment sample.

\section{Results}

\subsection{Extent of decomposition of the cadaver after 14 days}

At the time of placement (experimental day 0), the body was classed as being in the fresh stage of decomposition. On experimental day 1 , bloating of the abdomen became evident and by experimental day 6, the body had transitioned to complete bloat. After 14 days of placement at AFTER, the bloating began to subside and there were sections of the posterior in contact with the 
soil (namely the neck, upper back, and lower trunk/buttocks region), which still demonstrated the fresh stage of decomposition. However, active decay had commenced in the majority of the posterior soft tissue, causing leaching of fluids and a distinct CDI to form that was visible following movement of the body for collection of the sediment cores (Figure 1). In contrast, the anterior aspects of the head, neck and torso demonstrated differential decomposition in the form of desiccation by experimental day 14. Insect infestation of the body was prevalent throughout the study period, the most relevant of which being extensive maggot activity in the head and lateral and posterior regions of the torso.

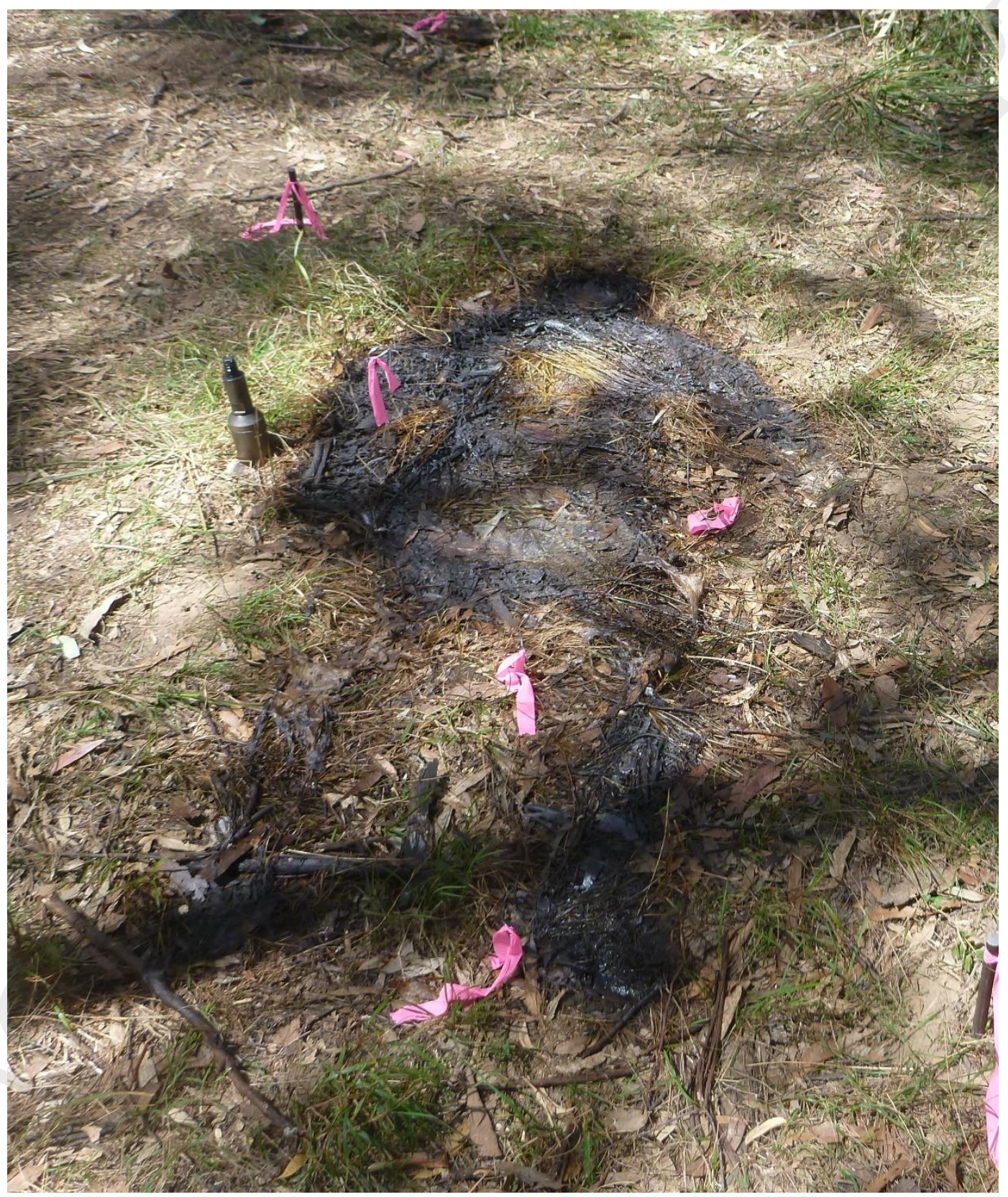

Figure 1: The observed CDI, subsequent to movement of the body for the collection of the sediment cores. 


\subsection{General description of the sediment strata}

In broad terms, the 'soil' component of each column consists of a dark brown organic-rich topsoil (the $\mathrm{O}$ and $\mathrm{A} 1$ horizons) in the uppermost $15 \mathrm{~cm}$ of each core, with the $\mathrm{A} 2$ and $\mathrm{B}$ horizons (predominantly sands with some silts and minor clays, variably coloured in shades of yellow, brown and grey) extending to depths below ground of approximately $30 \mathrm{~cm}$ and $80 \mathrm{~cm}$, respectively. The underlying $\mathrm{C}$ horizon consists predominantly of reddish-grey sandy silt and in situ weathered sandstone (saprolite), which was not sampled for analysis. Some sections of the columns (principally the B horizon) contain small gravels and have reddish-brown mottles (from iron staining), but none of the columns reached consolidated bedrock (the $\mathrm{R}$ horizon). The process of mechanical augering resulted in slight compression of three of the four control columns, creating a void space of a maximum of $5 \mathrm{~cm}$ depth at the top of these columns (Figure 2). This compression did not occur with the other sediment columns. We have not conducted a chemical analysis for purposes of soil classification, but present below some additional physical and physicochemical data to aid in the interpretation of the GC-MS/MS results.

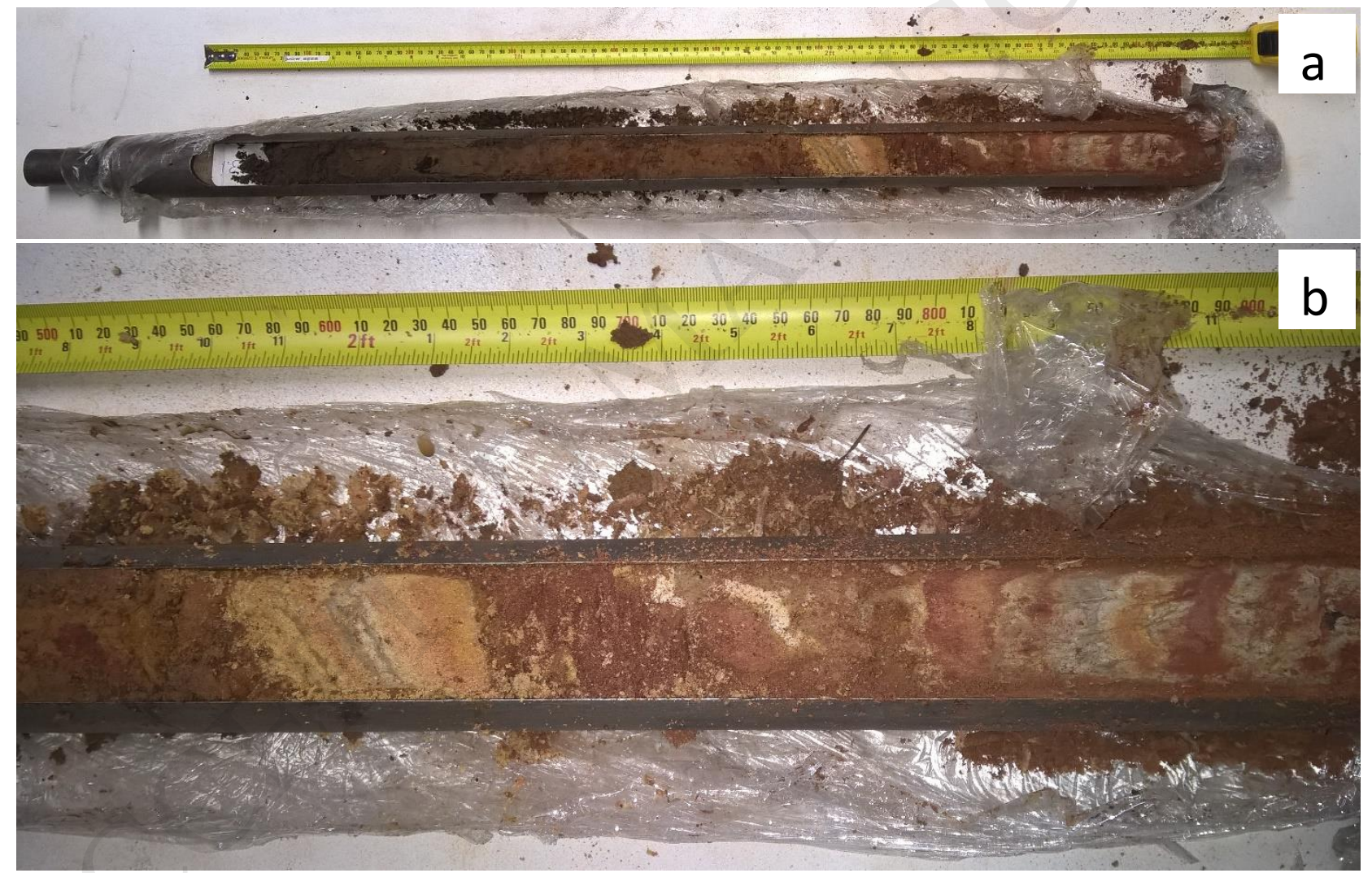

Figure 2: The third control sediment column (C-3) showing (a) the $1 \mathrm{~m}$ length with a $5 \mathrm{~cm}$ void at the top (due to compression caused by the augering process) and (b) close-up of the $0.5-0.9 \mathrm{~m}$ region of the column.

\subsection{Grain size, $p H$, Eh and EC of the soils and sediments}

The results presented in Figure 3 can be used to compare the sand, silt and clay composition, average grain size, $\mathrm{pH}$, Eh and EC of the soil and sediment samples relative to each other. In general, each of the samples were dominated by sand (37.60-75.64\%), followed by silt (21.75-48.01\%) and then clay (1.27-14.39\%). Some of the sand detected in the topsoil may consist of sand-sized organic matter. The ratios of sand, silt and clay were more consistent between each of the samples obtained 
from the C-3 control column compared to the samples in the C-1 column. Within each of the columns, the silt and clay compositions followed similar trends - that is, the compositions increased or decreased together (Figure 3a). The average grain sizes were comparable between soil and sediment samples found at similar depths below ground (Figure $3 \mathrm{~b}$ ). The trends observed for $\mathrm{pH}$ and Eh were similar between the two sediment columns, with collective $\mathrm{pH}$ and Eh ranges of 4.60-6.19 and 98-201 mV, respectively. The soil environments were more acidic and oxidising than the sediment samples from the underlying horizons, but at depths greater than $60 \mathrm{~cm}, \mathrm{pH}$ and Eh measurements were closer to what was observed for the soil samples (Figure 3c). The correlation between $\mathrm{pH}$ and $\mathrm{Eh}$ is presumably due to the $\mathrm{pH}$ dependence of the redox couples in the soil and sediments. As expected, EC measurements were the highest in the soil samples, corresponding to where the highest concentrations of soluble salts are found in each sediment column (Figure $3 \mathrm{~d}$ ).

\subsection{Slope of the plot}

Slope profiles were constructed for three transects running north/south across the plot. One transect passed through the middle of the torso, coinciding with the location of the origin core (Figure 4). The plot slopes slightly and steadily to the south, with an average gradient of $4.19^{\circ}$ for all three transects; the transect that ran through the middle of the torso has a slope of $4.23^{\circ}$.

\subsection{Weather data}

The temperature and rainfall data are presented in Figure 5. The temperature range was as expected for February. The minimum and maximum temperature ranges were $14.6-22.2^{\circ} \mathrm{C}$ and $25.6-$ $37.7^{\circ} \mathrm{C}$, respectively. The February mean minimum and maximum temperatures are reported to be $17.8^{\circ} \mathrm{C}$ and $29.2^{\circ} \mathrm{C}$, respectively, based on the Australian Bureau of Meteorology climate statistics data for 1993-2017 collected at the Richmond RAAF base, which is located approximately $13 \mathrm{~km}$ from AFTER [19]. It appeared to be uncharacteristically dry over the period of the study. Rain was recorded on only two days: day $2(10.4 \mathrm{~mm})$ and day $5(0.6 \mathrm{~mm})$. The mean rainfall for February from 1993 to 2017 is $115.5 \mathrm{~mm}$ (Richmond RAAF base), with 8.2 days of rain $\geq 1 \mathrm{~mm}$.

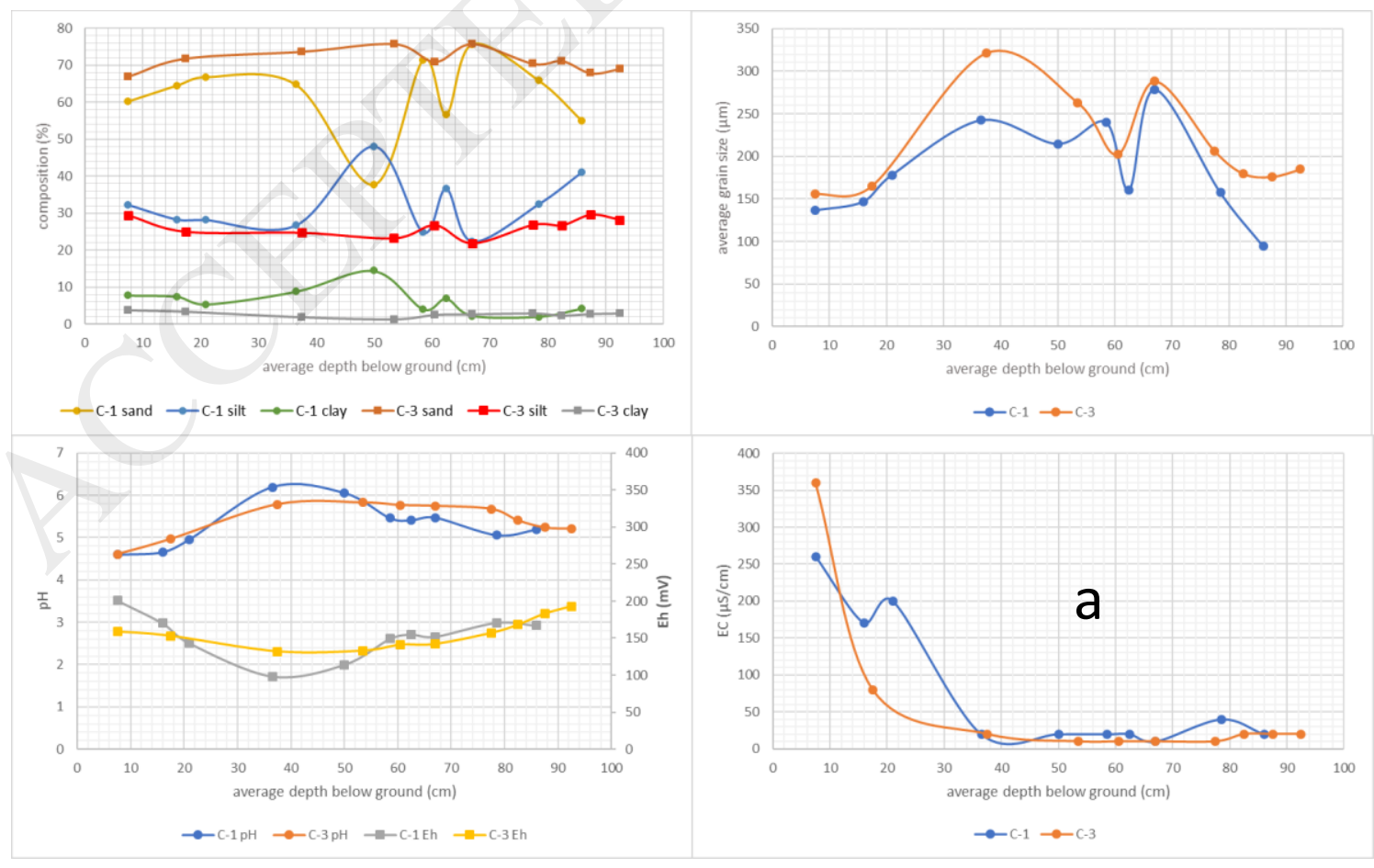


Figure 3: Plot of (a) sand, silt and clay composition, (b) average grain size, (c) pH and Eh and (d) EC against the average depth below ground, corresponding to the soil and sediment samples sectioned from the $\mathrm{C}-1$ and $\mathrm{C}-3$ control columns.

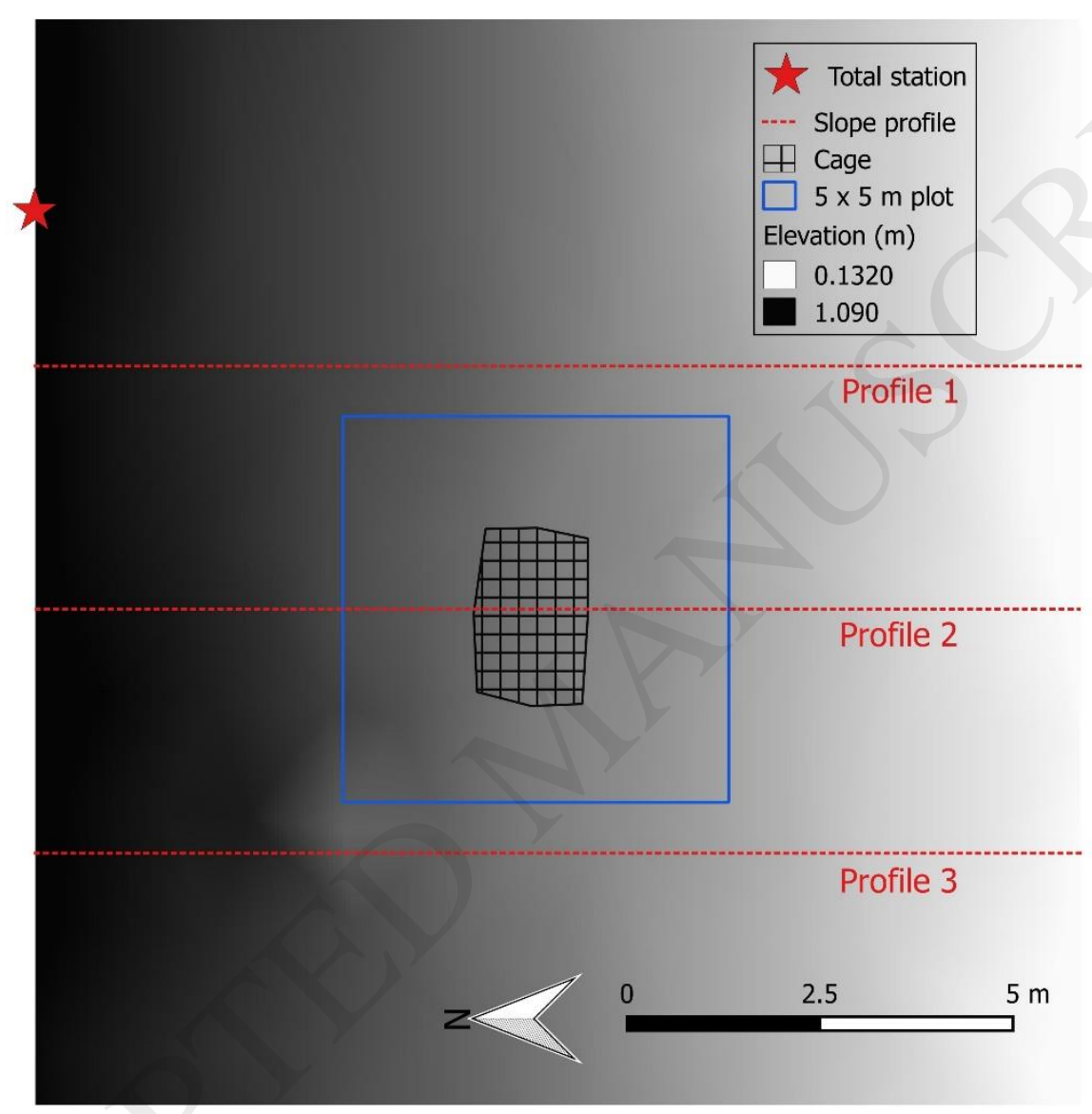



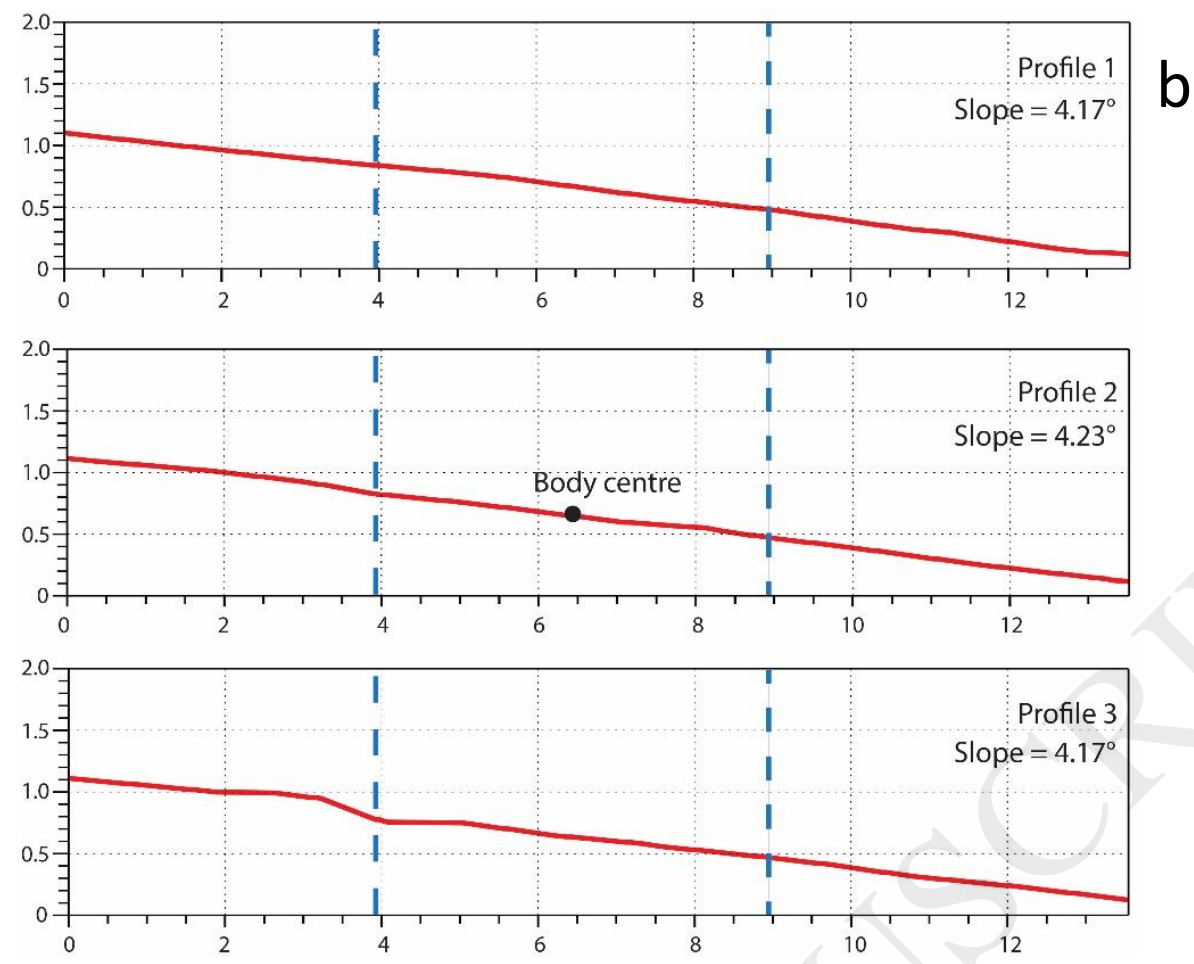

Figure 4: (a) Areas used to determine the slopes of the plot, relative to the positions of the total station and the cadaver, and (b) the corresponding slope profiles. For the latter, $\mathrm{X}$-axis $=$ distance from the northern boundary of the surveyed area $(\mathrm{m})$ and $\mathrm{Y}$ - axis = elevation above arbitrary datum $(\mathrm{m})$; the blue dashed lines indicate the northern and southern boundaries of the $5 \times 5 \mathrm{~m}$ plot.

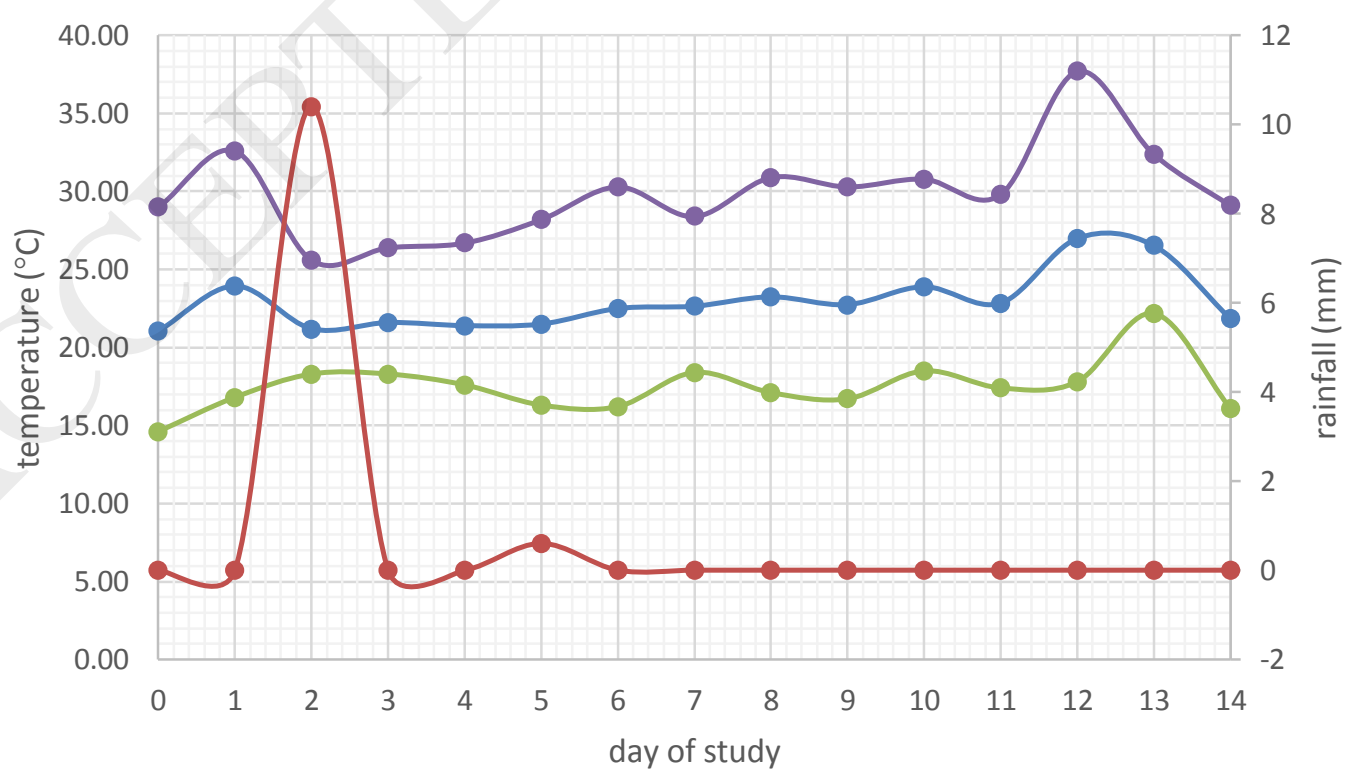

- average temperature - minimum temperature - maximum temperature - rainfall 
Figure 5: Temperature and rainfall data over the period of the study.

\subsection{Detection of cholesterol in the sediment samples}

\subsubsection{Sediment columns $(n=4)$ used as controls}

The hexane extracts corresponding to the samples taken from two of the control sediment columns (C-2 and C-4) contained either low (between the limits of detection (LOD) and quantification (LOQ) of the method, and therefore not quantifiable in the hexane extracts) or no detectable abundances of cholesterol, except for the sample corresponding to the $0-5 \mathrm{~cm}$ depth interval of column C-2. Approximately $13.2 \mathrm{ng} / \mathrm{g}$ of cholesterol was extracted from this sample, whereas cholesterol was found at relatively higher concentrations in most of the samples taken from the other two control columns (C-1 and C-3) (Figure 6). Cholesterol abundance appears to decrease as depth increases, but there may be more than one explanation for this trend. The presence of cholesterol in sediment is often associated with the deposition of organic materials, such as animal remains. Therefore, it is more likely found in the topsoil (which has a higher organic content [20]), with the concentration expected to decrease with increasing depth below the ground surface. This is also the case with fatty acid lipids, which are ubiquitous in soil [6]. Also, the sediment appeared to be more compacted with increasing depth, so the downward movement of percolating water may have been inhibited, reducing the extent of vertical leaching of cholesterol. The extraction efficiency of the method for different sediment substrates may have had some influence on the observed trend, but since the ratios of sand, silt and clay were quite consistent between each of the samples obtained from the C3 control column (Figure 3a), extraction efficiency is not considered a significant factor. Comparison of the sand, silt and clay compositions, average grain sizes, and $\mathrm{pH}$, Eh and EC data for the control samples (Figure 3) with the approximate cholesterol concentrations detected in these samples (Figure 6) showed that these factors had a minimal effect on the distribution of cholesterol through the sediment. The differences in cholesterol distribution in the control sediments are likely due to events that occur near some sediments but not others. Such events include (but are not limited to) the nearby deposition of animal remains (or not) and differential percolation of water.

Only 16 of the 36 control samples sectioned from four columns contained cholesterol in quantifiable concentrations, none of which exceeded $253 \mathrm{ng} / \mathrm{g}$ (Figure 6). The concentration ranges found in the soil (O and A1 horizons), A2 and B horizons were $0-253 \mathrm{ng} / \mathrm{g}(\mathrm{n}=8,74 \pm 129 \%$ relative standard deviation, RSD), $0-214 \mathrm{ng} / \mathrm{g}(\mathrm{n}=11,53 \pm 117 \% \mathrm{RSD})$ and $0-63 \mathrm{ng} / \mathrm{g}(\mathrm{n}=17,13 \pm 189 \% \mathrm{RSD})$, respectively; 'detectable' abundances below LOQ were given a value of zero for these mean and RSD calculations. 


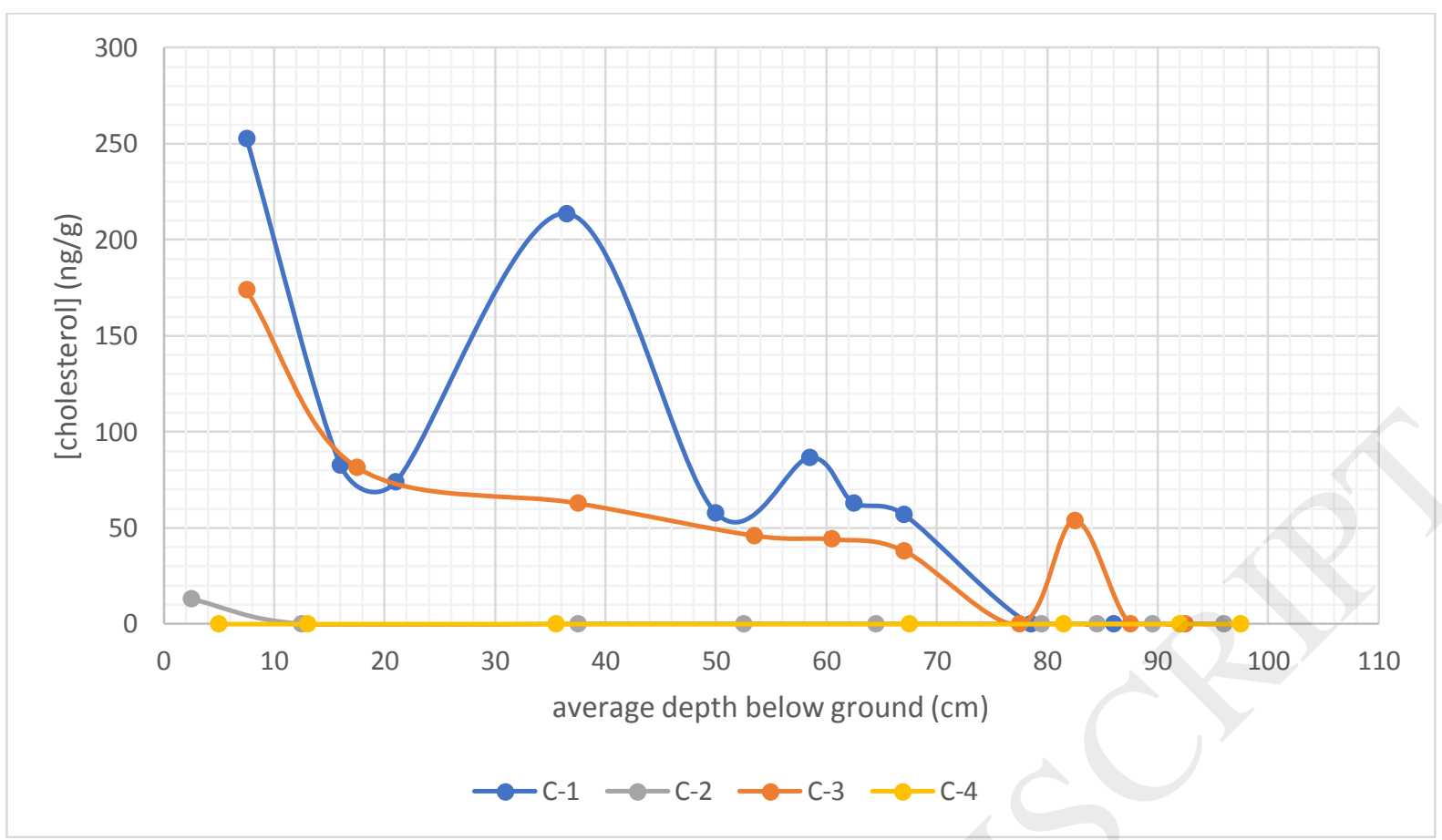

Figure 6: Approximate cholesterol concentrations found in the sediment samples taken from four of the control sediment columns.

Note: Average depths were determined as the arithmetic mean of the start and end depths of each sediment section taken from the columns.

\subsubsection{Sediment columns $(n=17)$ collected after cadaver placement}

A total of 290 samples were sectioned from the 17 cores. The density and distribution of cholesterol along the north/south and east/west transects are shown as two-dimensional profiles (i.e., distance from the centre of the torso and depth below the ground surface) in Figures 7 and 8, respectively. As with the control columns, cholesterol abundance appears to decrease as depth increases. However, the cholesterol abundances are spread across many more orders-of-magnitude than in the control samples and, for each of the three substrate horizons (i.e., soil, A2 and B horizons), the highest measured cholesterol abundance is significantly greater than in the control samples. The concentration ranges for the soil, A2 and B horizons are $0-177,941 \mathrm{ng} / \mathrm{g}(\mathrm{n}=47,16,590 \pm 200 \%$ RSD), $0-60,393 \mathrm{ng} / \mathrm{g}(\mathrm{n}=87,2686 \pm 361 \% \mathrm{RSD})$ and $0-1113 \mathrm{ng} / \mathrm{g}(\mathrm{n}=156,15 \pm 665 \% \mathrm{RSD})$. These data indicate that decomposition products penetrated through all three horizons; the extent of lateral and vertical movement is discussed in detail in the next section. 


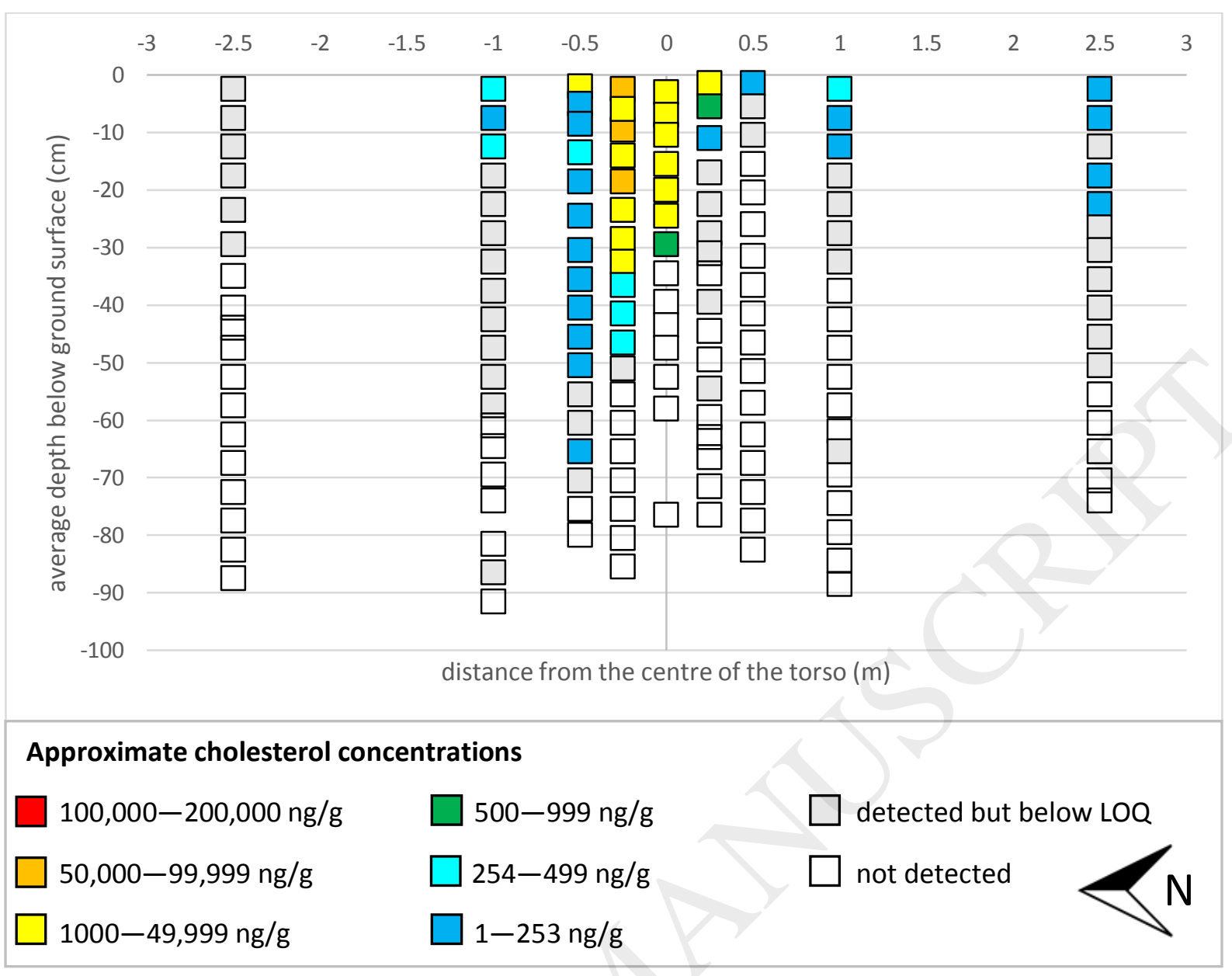

Figure 7: Cross-sectional profile of the sediment columns along the north/south transect, displaying the density and spatial distribution of cholesterol. The northern boundary of the plot is on the lefthand side; the plot slopes gently from north to south. 


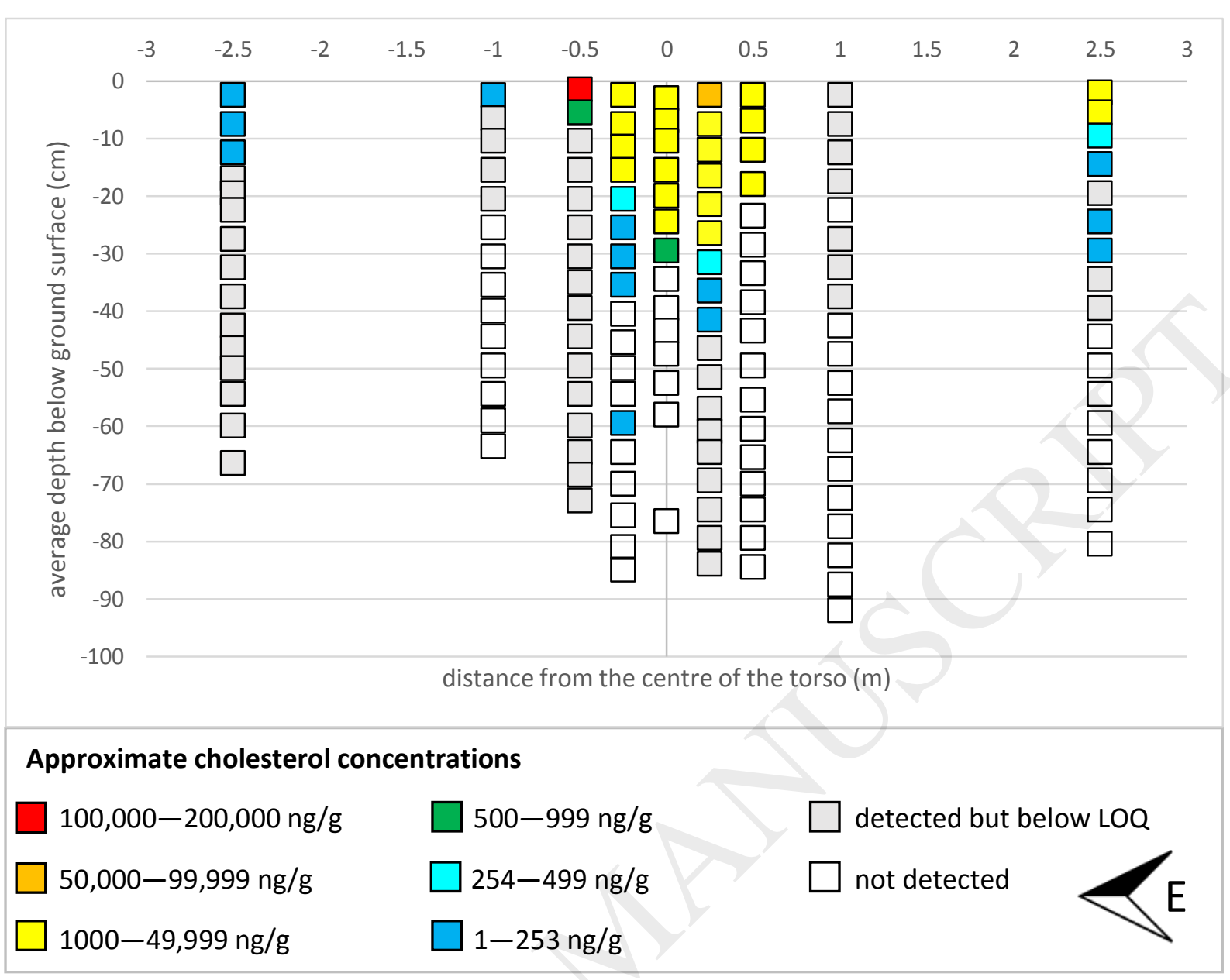

Figure 8: Cross-sectional profile of the sediment columns along the east/west transect, displaying the density and spatial distribution of cholesterol. The eastern boundary of the plot is on the lefthand side; the plot is essentially flat from east to west.

\section{Discussion}

\subsection{Experimental design}

A frozen donor was used for this study due to the lack of availability of non-frozen donors. The freeze/thaw process had minimal impact on the decomposition process relative to fresh donors placed in the same environment, based on comparison with donors that had previously arrived at AFTER on the same day as their death or following a short period in cold refrigeration (upwards of 20 surface donors at the facility for comparison). Since the remains were frozen for the entire period beginning soon after death until thawed in preparation for arrival at AFTER, the remains were still deemed to be in the fresh stage, as no major visible signs of external decomposition were evident. It is recognised that internal processes may have commenced, but based on the common stages reported for decomposition, the donor was classed as being in the fresh stage at the time of placement at AFTER.

As this study was conducted in the third month of the Australian summer, decomposition was expected to be accelerated compared to the cooler months, and 14 days was estimated to be an 
adequate period for substantial autolysis, putrefaction and leaching. After 14 days, however, decomposition had not progressed as rapidly as previously reported for animal remains in the same environment, and was more advanced on the anterior than the posterior.

Cholesterol was chosen as an alternative biomarker to fatty acids for monitoring the movement of decomposition products through soil and sediment, because cholesterol is less ubiquitous than fatty acids in this environment. When sub-sampling each section, natural sedimentary boundaries were respected so that any potential trends associated with the type of substrate could be identified. Because the sediment matrix changes with depth down the column, the preparation and use of at least three separate matrix-matched calibrator standards would be cumbersome. Consequently, solvent-only calibrator standards were used for ease and consistency. This approach was acceptable for this study as the 'true' concentration of cholesterol in each sediment sample was not important; the priority was to establish whether samples contained higher or similar/lower concentrations than those extracted from the control samples of similar substrate type (which are also from broadly similar depths). Alongside each batch of sediment samples, reagent blank and QC standards were also analysed to ensure that the analysis was performing as expected. A positive result for decomposition products was given if the cholesterol concentration in any particular sediment sample was higher than that detected in the control samples of similar substrate type.

\subsection{Extent of lateral leaching}

The slope of the plot was calculated to assess the effect of gravity-assisted diffusion on the movement of the decomposition products. Rain is another variable that may affect the movement of such products through sediment. Heavier rainfall was recorded on day $2(10.4 \mathrm{~mm})$ than on day 5 $(0.6 \mathrm{~mm})$ of the study, with both days overlapping with the start of the decomposition process. Accordingly, some influence of rain on the movement of decomposition products was expected, potentially in combination with the slight slope to the south.

The appearance of cholesterol in the soil samples is a good indicator of the extent of lateral leaching, since the highest measured concentrations were detected in this substrate layer relative to the underlying layers. The soil layer is also closest to the surface and less densely packed, so the underlying layers are expected to offer greater resistance to lateral (and vertical) leaching. Of the 17 sediment columns, 12 contained soil layers in which at least one sample had a measured cholesterol concentration of greater than $253 \mathrm{ng} / \mathrm{g}$ (i.e., more than the highest concentration detected in the control soil samples). The soil directly beneath the centre of the torso contained cholesterol concentrations well above this notional baseline value, but higher concentrations were found in soils further away, with the highest measured concentrations found $0.5 \mathrm{~m}$ east of the centre of the torso (Figures 7 and 8).

Along the north/south transect, horizontal movement of decomposition products was found to be between 1.0 and $2.5 \mathrm{~m}$ in both directions from the centre of the torso. The three soil samples from the $1.0 \mathrm{~m}$ northern column contained approximately $344 \mathrm{ng} / \mathrm{g}(2.5 \mathrm{~cm}$ average depth), $76 \mathrm{ng} / \mathrm{g}$ (7.5 $\mathrm{cm}$ average depth) and $363 \mathrm{ng} / \mathrm{g}$ (12.5 cm average depth) of cholesterol. Cholesterol was either below quantifiable concentrations or was not detected in the soil and sediment samples collected from the $2.5 \mathrm{~m}$ northern column; this is similar to the result obtained for two of the control columns and demonstrates that material leached from the cadaver did not travel as far as $2.5 \mathrm{~m}$ to the north (i.e., upslope), but potentially past $1.0 \mathrm{~m}$. In the southern direction (i.e., downslope), cholesterol was detected at quantifiable concentrations in the upper $22.5 \mathrm{~cm}$ of the $2.5 \mathrm{~m}$ column, albeit at very low concentrations $(6.3-62 \mathrm{ng} / \mathrm{g})$ for three of the five samples. These values lie within the range observed for the control samples, so we consider it likely that the cholesterol was not contributed by 
decomposition of the human remains; nevertheless, this cannot be definitively ruled out based on the cholesterol data alone. However, the upmost soil sample from the $1.0 \mathrm{~m}$ southern column contained approximately $294 \mathrm{ng} / \mathrm{g}$, indicating that decomposition products have travelled to at least $1.0 \mathrm{~m}$ from the centre of the torso.

The highest concentrations of cholesterol were found in the soil samples collected $0.5 \mathrm{~m}$ to the east of the middle of the torso (Figure 8). The sample closest to the surface (average depth of $1.5 \mathrm{~cm}$ ) contained the highest abundance of cholesterol of any sample analysed in this study (approximately $177,941 \mathrm{ng} / \mathrm{g}$ ), which is not surprising as this sediment column was taken within the CDI. Further to the east (1.0 and $2.5 \mathrm{~m}$ columns), the contribution of cholesterol from the cadaver is ambiguous (< $140 \mathrm{ng} / \mathrm{g})$, whereas cholesterol was found at relatively high concentrations $(1490-63,050 \mathrm{ng} / \mathrm{g})$ in the soil samples collected from the $0.25,0.5$ and $2.5 \mathrm{~m}$ columns to the west of the middle of the torso. Cholesterol was also detected to a depth of approximately $40 \mathrm{~cm}$ in the $1.0 \mathrm{~m}$ western column, but at concentrations below LOQ (Figure 8).

In summary, decomposition products moved laterally from the centre of the cadaver to the north and south by up to $1.0 \mathrm{~m}$ (or possibly $2.5 \mathrm{~m}$ to the south, bearing in mind the caveat above) and to the east and west by up to $0.5 \mathrm{~m}$ (and possibly further) and $2.5 \mathrm{~m}$, respectively. These relative distances are consistent with the placement of the body. The head was placed pointing east (with the top located $155 \mathrm{~cm}$ from the eastern perimeter), which is the direction of the least lateral leaching. The head is considered to be low in lipid content relative to the abdomen and lower limbs. Conversely, the lower limbs pointed west, with the feet located $169 \mathrm{~cm}$ from the western perimeter; this aligns with the direction of the greatest lateral leaching. The left and right sides of the cadaver were equidistant from the southern and northern perimeters of the plot, respectively. Because of this symmetry, the same lateral leaching distance was expected in both directions, assuming that the low-gradient slope of the plot has not assisted the diffusion of decomposition products to the south (i.e., downslope of the cadaver); this would appear to have been the case.

\subsection{Extent of vertical leaching}

In terms of vertical leaching of cholesterol, the greatest average depth that yielded a positive result for decomposition products was $46.5 \mathrm{~cm}$. This sample was obtained from the $44-49 \mathrm{~cm}$ section of the column taken $0.25 \mathrm{~m}$ north of the centre of the torso (Figure 7), and contained approximately $339 \mathrm{ng} / \mathrm{g}$ of cholesterol (i.e., above the upper limit of approximately $214 \mathrm{ng} / \mathrm{g}$ for the sandy-silt control samples). Figure 9 shows the zone around the cadaver where the presence of decomposition products is indicated by the elevated abundance of cholesterol relative to the control samples. As visually suggested by the $\mathrm{CDI}$, the sedimentary region associated with the greatest depth of vertical leaching is directly beneath the torso (see also Figures 7 and 8).

The asymmetrical leaching profile observed for the north/south transect (Figure 9a) is inconsistent with gravity- or rain-assisted movement of decomposition products downslope, as the highest concentrations occurred upslope of the middle of the cadaver. The elevated concentrations of decomposition products in the $0.25 \mathrm{~m}$ northern column and the shallower penetration into the sediments south of the cadaver reinforce the conclusion drawn from the lateral leaching data: namely, that the gentle slope of the plot does not greatly influence the diffusion of cholesterol, but might play some role in the low concentrations detected in the soil samples collected from the $2.5 \mathrm{~m}$ southern column. No sediment samples were taken beyond the southern perimeter of the plot, so we cannot comment on the spatial distribution or density of decomposition products past this point. 

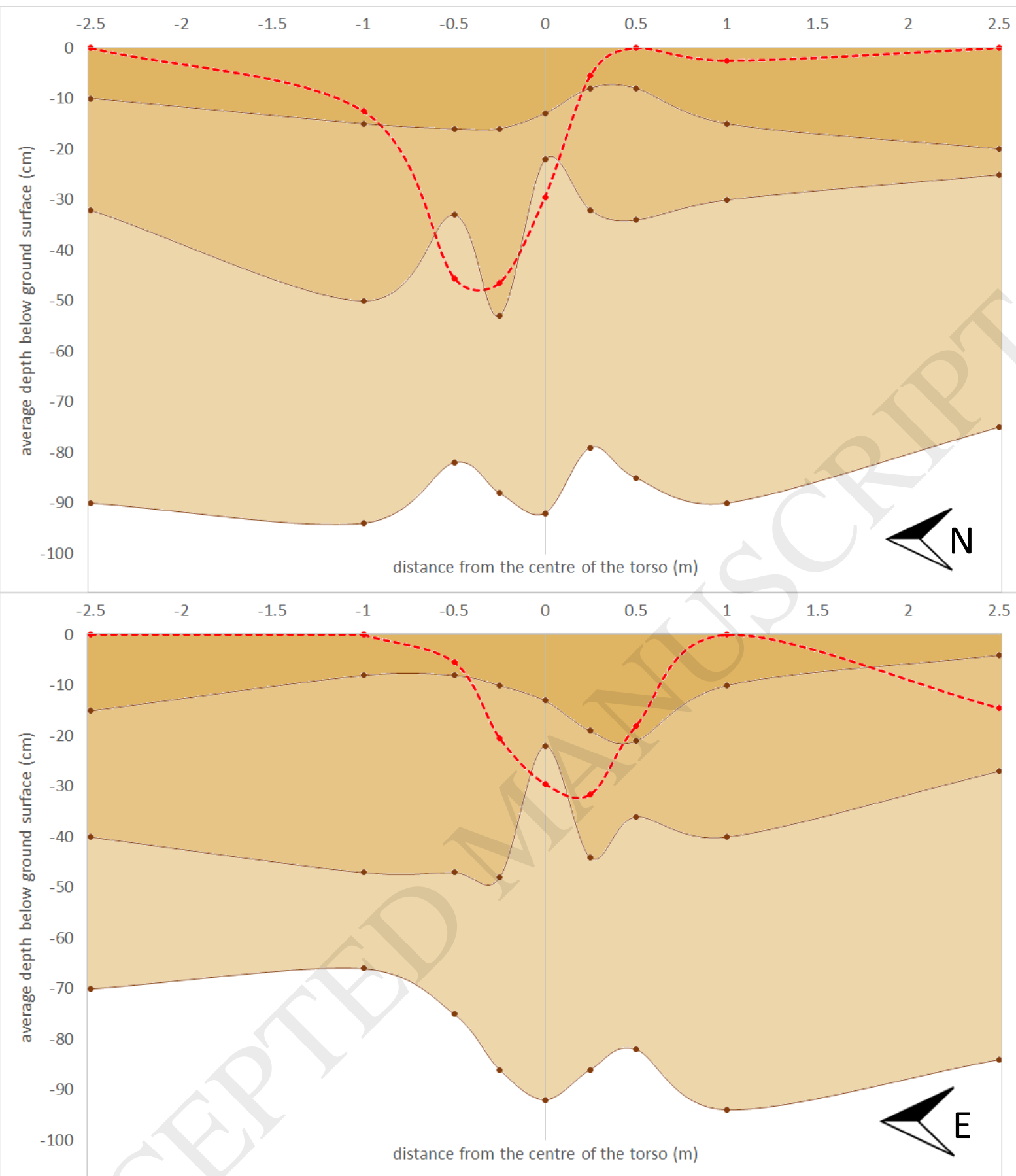

Figure 9: The probable zones of leaching (red dashed lines) around the cadaver along the (a) north/south transect and (b) east/west transect. The red data points points (through which the red dashed lines are fitted) correpond to the greatest average depths (below ground surface), yielding a positive result for decomposition products within each sediment column. The three beige bands correspond, from the shallowest to the deepest, to the soil (the $O$ and $A 1$ horizons), $A 2$ and $B$ horizons, respectively. The depths of the sedimentary boundaries were measured prior to sampling, and correspond to the brown data points. The underlying $\mathrm{C}$ horizon is uncoloured.

\subsection{Implications}


Based on the extent of lateral leaching, it is recommended that plot sizes used for human decomposition research should be a minimum of $5 \mathrm{~m} \times 5 \mathrm{~m}$. Furthermore, consideration should be given to placing the lower limbs so that they are further away from the perimeter of the plot compared to the head, thus allowing for the greater extent of leaching associated with the limbs. These measures should minimise contamination issues between adjacent plots and are essential if soil or sediment analysis is the focus of the research. The results for vertical leaching are relevant for plot monitoring, renewal and regeneration at both human decomposition research facilities and cemeteries. Our results indicate that the sediment substrate up to a depth of $49 \mathrm{~cm}$ below the cadaver is contaminated with the greatest abundance of decomposition products; perhaps this region should be the focus of long-term environmental monitoring experiments. From a forensic casework perspective, since the density and spatial distribution of the decompositions products can be explained by the positioning of the cadaver, there is scope for the use of soil and sediment leaching profiles to determine the original location of human remains if they have been moved or scavenged prior to discovery.

\section{Conclusions}

To gain insights into the extent of vertical and lateral movement of decomposition products through the soil and sediment underlying human remains, a cadaver classed as being in the fresh stage of decomposition was laid in the supine position on the surface of a plot at AFTER for 14 days in the Australian summer. Vertical leaching was detected up to a depth of $49 \mathrm{~cm}$ below the ground surface, with the greatest extent of penetration found directly beneath the torso. The largest distance of lateral leaching detected was $2.5 \mathrm{~m}$ from the centre of the torso. This coincides with the perimeter of the plot and the furthest distance from which sediment samples were collected. It is therefore possible, if not probable, that the distance of lateral movement exceeded $2.5 \mathrm{~m}$. The decomposition process was not as advanced as expected at the time of sediment collection, so even greater distances of movement of material may have occurred if further mass loss of the body had proceeded and more rain had fallen during the study period.

Further environmental monitoring studies should be carried out to obtain a more accurate perspective of the vertical and horizontal leaching distances in soils and sediments during, and subsequent to, the process of human decomposition. Such studies should use donors with a range of BMI scores and could usefully explore the variability observed in diverse climatic contexts for plots with a variety of substrate compositions, slopes and aspects. Long-term monitoring should also be carried out on the same plots (e.g., annually over a period of 7-10 years) to provide insights into the persistence and degradation of human remains in soils and sediments. These data can also be used to gain a deeper insight into the practical applicability of the use of leaching profiles for forensic casework. This study shows that there is scope for the use of GC-MS/MS cholesterol biomarker analysis for the detection of human remains, but more work is required to optimise the methodological approach so that it is as high-throughput and cost-effective as possible. The sophisticated instrumentation currently available provides for the straightforward and reliable detection of trace abundances of cholesterol. The issue lies with the time-consuming collection and sample processing of the sediment columns. Additional datasets may help refine the number of transects of samples that would need to be analysed before the presence of human remains can be confirmed. A compilation of cholesterol concentrations obtained from different substrate environments may also contribute towards the development of reference 'cut-off' concentrations that can be used as a guide to minimise false-positive results. 


\section{Acknowledgements}

This study was supported by the Australian Research Council through Australian Laureate Fellowship FL130100116 (R.G.R.). We thank Dr Maiken Ueland for supplying the weather data; Emma Flannery, Dr Mike Morley and Conor McAdams for assistance with the collection of the sediment columns; and Dr Sam C. Lin and Dr Alex Mackay for their help with acquiring the elevation data. 


\section{References}

[1] B.B. Dent, S.L. Forbes, B.H. Stuart, Review of human decomposition processes in soil, Environmental Geology 45(4) (2004) 576-585.

[2] M. Algarra, J.E. Rodríguez-Borges, J.C.G. Esteves da Silva, LC-MS identification of derivatized free fatty acids from adipocere in soil samples, Journal of Separation Science 33(2) (2010) 143-154.

[3] S.L. Forbes, B.H. Stuart, B.B. Dent, S. Fenwick-Mulcahy, Characterization of adipocere formation in animal species, Journal of Forensic Sciences 50(3) (2005) 633-640.

[4] S.J. Notter, B.H. Stuart, B.B. Dent, J. Keegan, Solid-phase extraction in combination with GC/MS for the quantification of free fatty acids in adipocere, European Journal of Lipid Science and Technology 110(1) (2008) 73-80.

[5] S.J. Notter, B.H. Stuart, R. Rowe, N. Langlois, The Initial Changes of Fat Deposits During the Decomposition of Human and Pig Remains, Journal of Forensic Sciences 54(1) (2009) 195-201.

[6] S.L. Forbes, J. Keegan, B.H. Stuart, B.B. Dent, A gas chromatography-mass spectrometry method for the detection of adipocere in grave soils, European Journal of Lipid Science and Technology 105(12) (2003) 761-768.

[7] S.L. Forbes, B.H. Stuart, B.B. Dent, The identification of adipocere in grave soils, Forensic Science International 127(3) (2002) 225-230.

[8] S.L. Forbes, B.H. Stuart, B.B. Dent, The effect of the method of burial on adipocere formation, Forensic Science International 154(1) (2005) 44-52.

[9] M. Larizza, S.L. Forbes, Detection of fatty acids in the lateral extent of the cadaver decomposition island, Geological Society, London, Special Publications 384(1) (2013) 209-219.

[10] J. Adachi, Y. Ueno, A. Miwa, M. Asano, A. Nishimura, Y. Tatsuno, Epicoprostanol found in adipocere from five human autopsies, Lipids 32(11) (1997) 1155.

[11] B. von der Lühe, L.A. Dawson, R.W. Mayes, S.L. Forbes, S. Fiedler, Investigation of sterols as potential biomarkers for the detection of pig (S. S. domesticus) decomposition fluid in soils, Forensic Science International 230(1) (2013) 68-73.

[12] K.A. Perrault, P.-H. Stefanuto, B.H. Stuart, T. Rai, J.-F. Focant, S.L. Forbes, Detection of decomposition volatile organic compounds in soil following removal of remains from a surface deposition site, Forensic Science, Medicine, and Pathology 11(3) (2015) 376-387.

[13] B.B. Dent, M.J. Knight, Cemeteries: A special kind of landfill. The context of their sustainable management. Groundwater: Sustainable Solutions, Conference of the International Association of Hydrogeologists, Melbourne, 1998, pp. 451 - 456.

[14] J.A. Aitkenhead-Peterson, C.G. Owings, M.B. Alexander, N. Larison, J.A. Bytheway, Mapping the lateral extent of human cadaver decomposition with soil chemistry, Forensic Science International 216(1) (2012) 127-134.

[15] F.E. Damann, A. Tanittaisong, D.O. Carter, Potential carcass enrichment of the University of Tennessee Anthropology Research Facility: A baseline survey of edaphic features, Forensic Science International 222(1) (2012) 4-10.

[16] J. Cassar, B. Stuart, B. Dent, S. Notter, S. Forbes, C. O'Brien, I. Dadour, A study of adipocere in soil collected from a field leaching study, Australian Journal of Forensic Sciences 43(1) (2011) 3-11.

[17] H.L. Dibble and S.P. McPherron, EDM Software. <http://www.oldstoneage.com/software/edmwin.shtml>, 2010 (accessed 2016).

[18] S. Luong, E. Hayes, E. Flannery, T. Sutikna, M.W. Tocheri, E.W. Saptomo, Jatmiko, R.G. Roberts, Development and application of a comprehensive analytical workflow for the quantification of nonvolatile low molecular weight lipids on archaeological stone tools, Analytical Methods 9 (2017) 43494362.

[19] Australian Bureau of Meteorology, Climate statistics for Australian locations- Summary statistics for RICHMOND RAAF. <http://www.bom.gov.au/climate/averages/tables/cw_067105.shtml>, 2017 (accessed 15/06/2017). 
[20] M. Tibbett, D.O. Carter, Soil Analysis in Forensic Taphonomy: Chemical and Biological Effects of Buried Human Remains, CRC Press2008. 